\title{
Report on the ad-hoc review of Episodes, memorandum of understanding (MoU) between the IUGS and the Geological Society of India
}

\section{Date and Venue of the Review:}

18-20 April 2015

Geological Society of India

Kavitha Apartments, No. 63, $12^{\text {th }}$ Cross, Basappa Layout, P.B. No. 1922, Gavipuram, Bangalore 560019, India

Informatics (India) Limited

R.V. Road, No. 194, Basavanagudi, Bangalore 560004, India

Pragati Graphics

$3346 / 27^{\text {th }}$ Road, Vijaya Nagar, Bangalore, Karnataka (West), $4^{\text {th }}$

Cross, Bangalore 560040, India

\section{Geological Society of India Participants:}

Dr. S.V. Srikantia, Vice President, Geological Society of India

Mr. R.H. Sawkar, Secretary, Geological Society of India

Dr. K.S.Godhavari, Secretary, Geological Society of India

Dr. M.S. Rao, Council Member, Geological Society of India

Dr. B. Mahableshwar, Editor, Geological Society of India

\section{Informatics Staff:}

Mr. N.V. Sathyanarayana (Chairman \& Managing Director)

Mr. S.A. Praveen (General Manager)

Pragati Graphics Staff:

Mr. Nagaraju (Owner)

IUGS Ad-Hoc Review Committee \& the Publication Committee Members:

Prof. Yildirim Dilek, Miami University, USA

Dr. Peter Bobrowsky, Geological Survey of Canada, Canada

Dr. Fareeduddin, Geological Society of India, Science Editor - EPISODES, India

Dr. Brian Marker, Chair, Publications Committee, U.K.

\section{Background and rationale for the review}

\section{A. Prelude to the onsite review}

Item 15 of the Memorandum of Understanding (MoU) between the International Union of Geological Sciences (IUGS) and the Geological Society of India (GSI) regarding the production of Episodes states that a regular review of the status of the journal has to be undertaken in a quadrennial time scale on a regular basis. The GSI agreed to take over the responsibility of publishing Episodes during the IGC-33 in Oslo in August 2008, and the related MoU was composed by the relevant parties at that time. This MoU was formally signed by the Former President, Alberto Riccardi, of the IUGS and the Secretary of the GSI, Mr. R.H. Sawkar, in the end of February 2009. It was subsequently renewed during the IGC-34 in Brisbane (Australia). There has not been a formal review of the MoU between the IUGS and GSI since its first implementation in 2009.

A formal, IUGS-led ad-hoc review of the Episodes MoU was requested at the Annual IUGS EC Meeting held in Vancouver (Canada) in October 2014. IUGS Vice President Yildirim Dilek was appointed to carry out this review process. Upon Vice President Dilek's notification and request, The IUGS Publication Committee Chair, Dr. Brian Marker, provided some documents regarding the publication record of Episodes during the past five years and scheduled, in consultation with Editor Fareeduddin and the GIS Secretary, the ARC meeting in Bangalore (India) in late April of 2015.

During the course of the ARC review in Bangalore, Vice President Dilek met with three of the IUGS Publication Committee members, Dr. Fareeduddin, Dr. Peter Bobrowsky (Canada) and Dr. Brian Marker (The U.K.), to discuss the current status of Episodes and a wide-range of issues related to its visibility and impact factor, publication media, budget, editorial board, and its modernization efforts. Following this meeting with the Publication Committee members, Vice President Dilek met with some of the executive committee members of the GSI for two days to review the history and the status of the current MoU. The subsequent visits with the staff members and owners of Informatics (India) Limited and Pragati Graphics provided important information about the various stages of the digital preparation of the publicationready journal in Bangalore.

This report presents a succinct account of the issues discussed during the onsite ARC review, and a series of recommendations regarding the future of Episodes as a viable, international journal in the broad field of geosciences. It also provides a list of some of the immediate and future actions, perceived as necessary, in order to maintain and follow a mutually agreeable MoU beyond 2016.

\section{B. Current memorandum of understanding $(\mathrm{MoU})$}

The current MoU was composed in the end of June 2012, and was signed by Former President Alberto Riccardi of the IUGS and the Secretary of the GSI, Mr. R.H. Sawkar, during the International Geological Congress-34, held in Brisbane, Australia, in August 2012. The content of this current $\mathrm{MoU}$ is exactly the same as in the previous MoU signed by the same IUGS and GSI officers in the end of February 2009, except that the total amount of the IUGS funds in support of the publication of Episodes was raised from US $\$ 23,000$ per year to US\$28,000 per year in the new MoU.

The binding terms of the current $\mathrm{MoU}$ are presented below as the necessary background and rationale of the ARC review. Those terms that are deemed as important and the subject of discussions during the onsite review are highlighted in italic and underlined in the current MoU below.

Terms of a Memorandum of Understanding between the International Union of Geological Sciences (IUGS) and the Geological Society of India (GSI) for the production of Episodes (effective as of August 2012):

1. The publisher of Episodes shall be IUGS, whose principal organ of publication is the journal.

2. The production and distribution of Episodes shall be the respon- 
sibility of the Geological Society of India, hereinafter GSI.

3. The journal shall be devoted to publishing reviews of topical issues in the Earth sciences and other contributions likely to have wide appeal to the international geoscientific community. As the principal organ of publication of IUGS, the journal shall also carry material desirable or necessary to achieve worldwide notification of the activities of the Union.

4. Subject to certain subsequently stated provisions, responsibility for the content, format, quality, and style of Episodes shall rest in the hands of an Editorial Team composed of the Editor, who shall be appointed by GSI in consultation with and approved by IUGS; Managing and Assistant Editors, who shall be selected by GSI and appointed in consultation with IUGS; and an Editorial Board of up to 30 Associate Editors (chaired by the Editor) appointed by IUGS with the full co-operation and support of the Editor. The Editor and Editorial Board shall seek to implement all relevant portions of the publication policy of IUGS.

5. The Editor, who should be an internationally distinguished Earth scientist with a wide range of multinational contacts, will have ultimate responsibility for the scientific content of the journal. The Managing and Assistant Editors, who should be broadly familiar with all aspects of scientific publishing, will be responsible to the Editor for technical and related matters. The Associate Editors, who should be internationally respected for accomplishments in their earthscience discipline or subdiscipline and to a substantial degree internationally based, will be responsible for soliciting manuscripts and for working co-operatively with the Editors to ensure an acceptably high quality and reliability in published material.

6. The language of publication of Episodes shall be English.

7. The print-run for the journal will be modestly in excess of the total number of individual and institutional subscribers and the number of individuals who should receive free copies. The IUGS Executive Committee, with advice from the Publications Committee (PC), GSI, and the Editor, will approve the free distribution list.

8. The practice of publishing a special edition of Episodes on the geology of the country or countries serving as host to an International Geological Congress will be continued, and the guest editorship of such a special edition may be delegated to one or more appropriate Earth scientists within the host country or countries. The cost of the special issue will be borne by the Organizing Committee of the International Geological Congress. Dependent on the availability and backlog of accepted regular submissions to the journal, and on the waiting period to publish these, the editors, in consultation with the IUGS PC, may agree to publish other special or theme issues of Episodes and may, if appropriate, delegate the editorship of these to suitably qualified persons. Special or theme issues may be published in addition to regular issues, however, only when the necessary funding is available or has been contributed by a party wishing to have the special issue. The funding of special issues must not be allowed to detract from that of the regular issues. It is anticipated that the number of special or theme issues will be small.

9. GSI will undertake to produce Episodes in four regular issues per calendar year, together with any special issues that may be deemed appropriate from time to time and for which adequate funding is available; to ensure so far as possible that each regular issue is of the order of eighty (80) pages in length and is released promptly at one of the quarterly intervals (March, June, September, or December); and to maintain or enhance the quality of production of the existing journal, including that of its attractive cover.

10. GSI will undertake further to work co-operatively with the Editor(s) and Editorial Board of the journal, and with the Publications Committee and Executive Committee of IUGS in ensuring the future success of Episodes; in increasing institutional and individual subscribers to the journal; in seeking and accommodating appropriate, paid advertisements, and in accommodating these in the journal, together with other unpaid advertisements of publications arranged by reciprocal agreement with other Earth-science publishers and associations.

11. GSI will maintain the web posting of back issues of Episodes to the web site www.episodes.co.in and also uploading of PDF files of the full articles immediately after Episodes publication.

12. In consultation with the IUGS Publications Committee, GSI will investigate the full online presentation of Episodes through a medium such as Geoscience World or some other appropriate, fully searchable web-based publication, with the aim to full transition to this format of publication by 2013-2014.

13. GSI agrees to cover all costs of production and distribution of Episodes on the condition that IUGS supports this process through an annual allocation of 28,000 US Dollars.

14. IUGS undertakes to encourage the publication in Episodes of appropriate material of high quality from its various bodies, programs, and affiliated organizations, and to lend all feasible support to both GSI and the journal's Editors and Associate Editors in ensuring the future success of the journal. IUGS wishes to see all parties concerned with Episodes work together in collaborative and effective fashion as a cohesive team, and it undertakes to do its part in achieving this end.

15. This Memorandum of Understanding will remain in force from the date of its formal initiation through 2016, unless either IUGS or GSI wishes to cancel the agreement before that date due to extraordinary circumstances. Regardless of the circumstances, the agreement shall not be terminated without a formal review of the status of the journal within IUGS and GSI with the circumstances demanding the cancellation. Such an extraordinary review should not be confused with the regular quadrennial review of the status of the journal conducted by IUGS and due before the next International Geological Congress. The next regular review should be held in late 2013 or early 2014.

\section{Review and discussions}

\section{A. Status of Episodes and outlook}

A-1: Episodes is the flagship journal of IUGS and is published quarterly every year. Nearly $70 \%$ to $90 \%$ of its content per issue consists of science papers (original and review in nature), and the remainder includes conference reports, IUGS activities and working group contributions, book reviews, geological maps, IUGS ad-hoc review reports, and obituaries. Thus, Episodes is highly diverse in its coverage, which sets it apart from many other mainstream international journals in the broad field of earth sciences. Considering the current landscape of journal publications in earth sciences that is pre-dominated largely by professional organizations (AGU, GSA, GSL) and several commercial companies (Elsevier, Springer), it is difficult for 
Episodes to compete with most of the top journals in attracting highprofile science papers as a non-specialist venue. A focused search conducted by the Publication Committee shows that there is a tendency for specialist journals to have higher impact factors than those journals that publish papers on a wide range of topics. However, there is a good number of generalist journals, which have been historically and most recently highly successful. When we look at the records and the publication modes of some of these generalist journals, we see an important pattern to their success: they publish 12 issues per year, run a highly efficient online submission system, have an effective review and publication system in place, provide fast-track publication of invited, high-profile papers by established scientists, and put out nearly purely scientific contents (one exception is Elements) on a regular basis, instead of a highly erratic and irregular coverage as Episodes does.

The data in Table 1 show that Episodes trails behind as a generalist journal. In order for us to improve the visibility and rankings of Episodes, we must consider its mission and target readership carefully. One relevant question is whether Episodes should aim to serve the highly diverse IUGS community in highly irregular modes of content coverage, or to serve science to the wider geoscience community in a sustained, regular mode of publication.

There are also some positive improvements, however, regarding the recent status of Episodes. The number of manuscript submissions has increased from 38 in 2010 to 69 in 2014, and this positive trend has continued into 2015. The rejection rate for submitted manuscripts has increased in parallel with the increased number of submissions (nearly $60 \%$ rejection rate nowadays), and this shift has raised the quality of the published papers in the journal. Its Impact Factor has been on par with that of some of the generalist journals in recent years (Table 2). The increased submission and impact factor numbers may likely be a factor of thematic special issues, which have attracted high-profile papers by internationally recognized scientists. The dramatic drop in its impact factor in 2012 has been interpreted as a result of the delayed publication of a journal issue.

Table 1: Comparative analysis of several top generalist journals in geological sciences in terms of their dashboard indicators (source of data: Brian Marker)

\begin{tabular}{|c|c|c|c|c|}
\hline Journal & SJR & H index & Total refs & $\begin{array}{c}\text { Total cites } \\
\text { (3 years })\end{array}$ \\
\hline Geology & 3.11 & 134 & 9.145 & 4.148 \\
\hline Episodes & 1.067 & 48 & 1625 & 213 \\
\hline Elements & 1.64 & 35 & 5,656 & 441 \\
\hline Geological Magazine & 1,89 & 55 & 2.726 & 434 \\
\hline Terra Nova & 1.51 & 57 & 2.822 & 473 \\
\hline
\end{tabular}

A-2: In our efforts to raise the visibility of Episodes among the mainstream international journals and to make it a contemporary journal, our discussions should also focus on how to phase it into the online publishing world efficiently and effectively within a short period of time. Item \#12 of the current MoU clearly states that this transition should have been made by 2013-14.

$A$-3: In addition to its obvious benefits and necessity of going online as a contemporary journal, there is another important factor in regard to its digital production and dissemination that has strong ramifications for the Episodes budget. The GSI spent US\$15,030 in 2014 for postage stamps for shipping the print copies of the journal issues to the subscribers and other recipients around the world. This expenditure is more than half of the total IUGS allocation to the GSI for the production and distribution of Episodes. Outdated and invalid postal addresses on the already shipped issues result in their return to the GSI by the Indian Postal Service, further increasing the shipment costs substantially. This significant drain in the journal budget would be eliminated when Episodes become available on a designated and well operating online system.

A-4: The fact that Episodes does not have a truly modern on-line system to streamline the submission, review, and revision stages of the processing of manuscripts does not allow the authors to keep track of their submitted manuscripts, and to have fast access to their accepted manuscripts digitally as in-press papers. This situation is a serious deterrence for many potential contributors in the academic world from their consideration of Episodes as a viable venue to publish their interesting scientific work, new data and innovative ideas. The lack of DOI numbers on papers published in Episodes is also a big negative for today's earth scientists, who would like to have their papers readily accessible and trackable in a digital form anywhere in the world. Thus, DOI registration of each paper in Episodes is critical in raising the journal's profile, and the IUGS should make every effort to ensure that this registration gets done in a timely and effective ways.

$A$-5: Item \#10 of the MoU states that the GSI shall make concerted efforts, in cooperation with the Editor(s) and Editorial Board of the journal, and with the Publications Committee and Executive Committee of IUGS, for seeking and accommodating appropriate, paid advertisements in order to raise revenues and additional funds for Episodes. The number of paid advertisements in the journal and hence of the related "outside funds" (non-IUGS and author page charges) has been miniscule during the last four years.

\section{B. Issues about the MoU and looking ahead}

B-1: Both the current $\mathrm{MoU}$ and its 2009 precursor contain some terms and conditions that appear to be internally conflicting, causing erroneous perceptions pertaining to the budgetary issues for the pro-

Table 2: Comparative analysis of Impact Factors of some of the generalist journals between 2008 and 2014 (source of data: Brian Marker)

\begin{tabular}{|c|c|c|c|c|c|c|}
\hline Impact Factor & 2008 & 2009 & 2010 & 2011 & 2012 & $2013 / 2014$ \\
\hline Geology & 3.887 & 4.368 & 4.026 & 3.612 & 4.087 & 4.638 \\
\hline Episodes & 1.870 & 2.122 & 2.041 & 1.282 & 0.950 & 1.384 \\
\hline Elements & 3.069 & 3.597 & 3.105 & 2.423 & 3.156 & 4.500 \\
\hline Geological Magazine & 1.853 & 2.059 & 2.207 & 1.764 & 2.270 & 2.177 \\
\hline Terra Nova & 1.899 & 2.087 & 2.164 & 2.339 & 2.830 & 2.321 \\
\hline
\end{tabular}


duction and distribution of Episodes. While the MoU clearly states that "the production and distribution of Episodes shall be the responsibility of the Geological Society of India" (Item \#2), which is supposed to accomplish this task by "covering all costs of production and distribution of Episodes on the condition that IUGS supports this process through an annual allocation of 28,000 US Dollars" (Item \#13), it is also explicitly mentioned in the MoU that "GSI would undertake to produce Episodes in four regular issues per calendar year, together with any special issues that may be deemed appropriate from time to time and for which adequate funding is available (Item \#9)". Item \#8 further elaborates on this matter by stating that "special or theme issues may be published in addition to regular issues, however, only when the necessary funding is available or has been contributed by a party wishing to have the special issue. The funding of special issues must not be allowed to detract from that of the regular issues". Here, the GSI interprets these statements independently of the contents of Items $\# 2$ and \#13, and expects to receive additional funds beyond the total of $\$ 28,000$ provided by the IUGS in order to produce and distribute any special issue (particularly if/when such special issues are significantly longer than the 80-page limit), even though these special issues ( 1 or 2 per year) replace the regular, quarterly issues, instead of being published as extra issues. The IUGS perceives, on the other hand, that the language of Item \#13 is clear enough to have the GIS responsible for the production and distribution of any special issue(s) without any additional funds from it (IUGS).

$B$-2: This discrepancy in the interpretations of the different terms of the MoU by the IUGS and the GSI has recently resulted in an unresolved dilemma when the overall production budget for Episodes ended up with having a deficit of $\$ 3,801$ due to the publication in 2014 of a special issue on Geohazards, which was longer than 80 printed pages. Item \#9 in the MoU indicates that "each regular issue is expected to be in the order of eighty (80) pages in length". But, it does not say anything about an expected or mandated length of a special issue. This internal conflict in the MoU in regard to the publication costs of special issues has to be eliminated with clear statements about how their production costs would be covered in order to avoid any future problems. In the meantime, it is overwhelmingly clear that GSI expects UGS to cover the current deficit of $\$ 3,801$ as well as any potential additional publication costs of the impending special issues.

B-3: The publication of thematic special issues has served Episodes very well in the past by raising its visibility and impact factor. The continued discussions of the Publication Committee over the last three years have also stressed the significance of these thematic special issues as a great service for the international readership and as an effective vehicle for maintaining a high impact factor through highprofile papers on frontier topics and on timely overviews. It is, therefore, extremely important that an appropriate level of funding is available for the production of two special issues per year. The publication of two special issues per year will also allow the Editor of the journal to be more selective in accepting papers for publication from a larger pool of volunteered contributions in Episodes.

$B-4$ : The GSI is of the opinion that the current level of funding by the IUGS in the amount of $\$ 28,000$ has been inadequate to offset the increasing costs of production and publication during the last several years. The fast climbing inflation rates in India, rising fees to pay for staff salaries, and recent hikes in postage charges have apparently strained the existing budget. Looking ahead, the GSI requests an initial US $\$ 5,000$ increase in the total IUGS allocation for the production and distribution of Episodes with a new MoU in effect as of 2016, and a yearly $10 \%$ increase in the total budget thereafter.

B-5: The June 2016 issue (\#2) of Episodes is allocated to the IGC35 (South Africa) special issue, which is anticipated to be about 400 pages long with a hard cover. About 10,000 copies of this special issue are to be printed. The GSI expects a budget of US $\$ 40,000$ to cover the costs of production and distribution of this special issue. The GSI also expects to receive the digital files of all 20 chapters in this special issue on "Mineral Fields of Africa" by December 1, 2015, in order for its timely production of this book before IGC-35 in South Africa.

\section{Conclusions and recommendations}

The IUGS Executive Committee, the IUGS Publications Committee and GSI recognize the significance of Episodes as one of the two major public faces (the other one being the IUGS Website) of the IUGS and a highly valued service to the international earth science community. The publication-distribution of Episodes by the GSI during the last seven years has promoted and facilitated excellent symbiotic working relationships between the IUGS and GSI that both organizations deeply value. This first formal review of the MoU (since its inception in 2008) between these two organizations in regard to the publication and distribution of Episodes has shown the hard work done by all parties involved in its preparation and production as well as the shortcomings of the current MoU.

Based on this ARC review, the following recommendations are submitted for consideration by the IUGS Executive Committee:

1. The IUGS Executive and Publication Committees should work in tandem to redefine the purpose and mission of Episodes in light of the fast evolving "publication sphere" in the broad field of geological sciences. This task is urgent and must be done prior to IGC-35 (South Africa), and should result in a clearly explained statement about the "Scope and Mission of Episodes".

2. Episodes, as the flagship journal, should become a truly online journal with an effectively working system for electronic submission, review and revision stages for manuscript submission. This online transition should have been accomplished in 2013-14 as the current MoU mandates, but it was not. Both the IUGS EC and the GSI must follow their previous agreement on this subject and should make all the provisions and efforts to put in place a viable online system prior to IGC-35.

3. With the full implementation of a viable online system for Episodes, the publication and distribution of print copies of the journal should be ceased in a staggering mode and should be entirely halted in the end of 2016. This action shall result in savings well over US\$15,000 per year that can in turn be used towards the online production services of the journal.

4. Since the onsite ARC review was completed in the end of April 2015, the IUGS EC and Secretariat have taken, in consultation with Vice President Y Dilek, the urgent and appropriate measures to register for Cross-Reference and DOI numbers for each paper published in Episodes. From now on, the IUGS is responsible for the payment of the relevant registration fees for DOI numbers, and the GSI is responsible for applying and securing the DOI numbers in a timely fashion, 
to be in effect at the latest for the December 2015 issue of the journal.

5. The IUGS EC should examine the current MoU carefully in line with the implementation of Recommendations \#1 through \#4 above, and with the content of Section II (Review and Discussions) of this ARC Review, and should compose, in consultation and co-operation with the GSI, a new MoU in order to put in place internally coherent, unambiguous and realistic terms. This new MoU should be clear in its language in regard to the:

(i) publication of special and thematic issues and the related budget coverage;

(ii) online operation of the journal production and the related budget coverage;

(iii) payment of the Cross-Reference and DOI registration fees by the IUGS, and the securement of a DOI number for each and every scientific paper published in Episodes in a timely fashion by the GSI;

(iv) total amount of the yearly budget allocation to the GSI for the production of Episodes that would consider the likely and realistic increases in production costs due to a number of factors outlined earlier in this report.

6. The IUGS and the GSI should work closely and co-operate on obtaining external revenues for the production of Episodes through paid advertisements and other funds from mining and petroleum companies, universities, NGO s and governments. The success of such fund-raising efforts will be critical in maintaining and further increas- ing the viability and visibility of Episodes as an international journal.

7. The IUGS Publications and Executive Committees should work in tandem to:

(i) renew the Editorial Board (Associate Editors) every two years in order to bring new expertise and diverse international coverage into the editorial team;

(ii) identify interesting, exciting and frontier hot topics for special and thematic issues of the journal, and the potential guest editors for these special issues;

(iii) identify scientific "Cover Articles", one for each issue, by well recognized, international scientists to raise the profile of the journal. These cover articles should be given the privilege of publishing colour illustrations at no charge to their authors.

I would like to thank the Geological Society of India (GSI), particularly Dr. Fareeduddin (Editor, Episodes) and Mr. Ramakrishna Sawkar (Secretary, GSI), for their warm hospitality during the onsite review in the GSI headquarters in Bangalore.

Respectfully submitted.

Yildirim Dilek

Vice President, IUGS \& Chair - ARC Committee 19 October 2015 